\title{
A Robust Technique of Face Recognition Algorithm for Automated Attendance Management System
}

\author{
Sekar. R, A. Sravani, P. Divya, S K. Mujeeb
}

\begin{abstract}
We recommend a robotized participation the board framework in this paper. This framework, in view of face identification and acknowledgment calculations, naturally distinguishes the understudy when he enters the homeroom and, by remembering him, denotes the participation. This paper depicts the framework design and calculations utilized in each stage. To assess the presentation of various face acknowledgment frameworks, diverse constant situations are considered. This paper likewise proposes the procedures to be utilized to manage dangers, for example, parodying. This framework spares time contrasted with conventional participation markings and furthermore helps screen the understudies.
\end{abstract}

Keywords- Face Acknowledgment, LBP, SVM.

\section{INTRODUCTION}

A face acknowledgment program is a product application that can perceive or confirm an individual from a video source's advanced picture or video outline. One approach to do this is to relate chosen picture facial highlights with a face database.

A face acknowledgment framework is a product application equipped for perceiving or confirming an individual from the advanced picture or video casing of a video source. One approach to do this is to consolidate chosen facial highlights of the picture with a facial database. When all is said in done, mechanized participation frameworks depend on bio-metric, keen card and online frameworks. Crosswise over different associations, these gadgets are usually utilized. Present day participation stamping strategy is very tedious and troublesome when there is more vitality. Participation Framework mechanization outweighs conventional strategies as it spares time and can likewise be utilized for security purposes. This additionally abstains from misdirecting interest.

Revised Manuscript Received on October 22, 2019

Sekar. R, Assistant Professor, Department of ECE, Koneru Lakshmaiah Education Foundation (Deemed to be University), Vaddeswaram, Guntur-Dist, AP.

A. Sravani, UG Scholar, Department of ECE, Koneru Lakshmaiah Education Foundation (Deemed to be University), Vaddeswaram, Guntur-Dist, AP.

P. Divya, UG Scholar, Department of ECE, Koneru Lakshmaiah Education Foundation (Deemed to be University), Vaddeswaram, Guntur-Dist, AP

S K. Mujeeb, UG Scholar, Department of ECE, Koneru Lakshmaiah Education Foundation (Deemed to be University), Vaddeswaram, Guntur-Dist, AP.

Email : shekharmohith09@kluniversity.in, 160040041@kluniversity.in, 160040673@kluniversity.in, 160040825@kluniversity.in.
For our situation face, a participation the executives framework created utilizing bio-measurements for the most part comprises of Picture Securing, Database Creation, Face Recognition, Pre-Handling, Extraction of Highlights, and Post-Preparing Phases of Arrangement. The accompanying segments in this paper are writing study, nitty gritty depiction of various stages in the proposed model, results and ends, and extension for development.

A face acknowledgment program is a product application that can perceive or confirm an individual from a video source's advanced picture or video outline. One approach to do this is by coordinating the picture's chosen facial highlights with a face database.

\section{LITERATURE SURVEY}

The creator B. K. Mohamed and C. Raghu, title as "Unique finger impression participation framework for homeroom needs," proposed in India as Face acknowledgment is a key zone in numerous applications, one of which is participation the board framework. Nowadays taking the understudy's participation in the study hall had become a dreary activity for instructors including getting out their names hanging tight for reaction and holding the participation up to the month to create participation report. This permits the face discovery and acknowledgment module to distinguish faces from the camera's caught picture and store the face picture. The creator T. Lim, S. Sim, and M. Mansor, Taking the understudy's participation in the study hall nowadays had become a dull activity for instructors including getting out their names hanging tight for answers and holding the participation up to the month to deliver participation report. It makes it feasible for the face location and acknowledgment module to recognize faces from the recorded picture of the camera and to store the face picture. This is a full grown innovation that has been normally utilized as a major aspect of their robotization frameworks by different associations. In this examination, to make a period participation the executives framework, a RFID-based framework was assembled.

S. Kadry and K. Smaili, Iris acknowledgment check is one of biometrically one of the most dependable strategies for individual ID. Some of its applications have been proposed to date with the fast improvement of iris acknowledgment check, including time participation framework, and so forth. In this paper, utilizing Daugman's calculation, a remote iris acknowledgment participation the executives framework is structured implemented.[15]This application-based biometrics and 
remote method takes care of the issue of fake participation and the issue of laying the comparing system. It can make it simpler and increasingly helpful for clients to partake.

The paper depicts the techniques used to approve an iris acknowledgment framework and remote transmission just as to fuse such a framework through a remote iris acknowledgment participation the executives framework. This machine has iris acknowledgment capacities to approve, autonomously test participation, and remote correspondence, etc. It framework's quality serves the ordinary participation the executives needs of various organizations and establishments. It has great possibilities for the market. Despite the fact that chip and PC innovation is growing quickly, no new techniques ought to be utilized in such a procedure, for instance. RFID innovation and different biometrics advancements, for example, retinal confirmation to improve recognizable proof exactness and embrace new remote advances, for example, GPRS to tackle the issue of low quality channel transmission, and so on.

\section{PROPOSED MODEL}

The structure of the framework is appeared in Figure 1. The proposed framework for programmed participation the board depends on a calculation for face acknowledgment. At the point when an individual enters the study hall, the camera at the passageway catches his picture. For further handling, the face district is then removed and pre-prepared. Since close to two individuals can enter the study hall at once, the calculation for face discovery has less work. Face acknowledgment demonstrates to be worthwhile than different frameworks as talked about in Table I. It is bolstered to post-handling when the substance of the understudy is perceived. The calculation of the procedure is examined.

As appeared in Figure 1, the phases in the proposed Computerized Help The executives Framework are. The following parts address specialized subtleties of the execution of each level.

\section{A. Image Capture}

The camera is mounted to catch the understudies frontal pictures a good ways off from the passage. The picture caught is liked to be $640 \times 480$ in size to abstain from resizing the picture in the back-end as we watched resizing can in some cases lead to terrible showing.

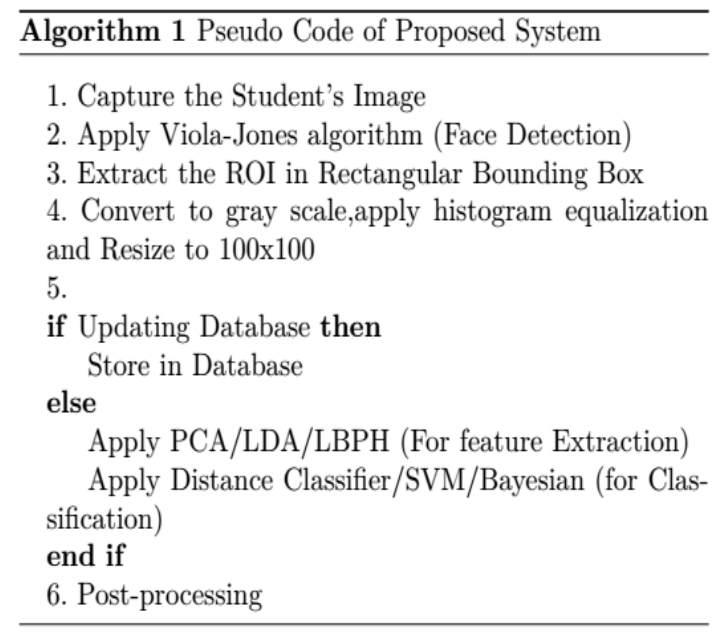

TABLE I Drawbacks of various Attendance Systems

\begin{tabular}{|l|l|}
\hline $\begin{array}{l}\text { Type of the } \\
\text { System }\end{array}$ & Drawback \\
\hline RFID-based & $\begin{array}{l}\text { Fraudulent us- } \\
\text { age }\end{array}$ \\
\hline $\begin{array}{l}\text { Fingerprint- } \\
\text { based }\end{array}$ & $\begin{array}{l}\text { Time } \\
\text { Consuming } \\
\text { for students } \\
\text { to wait and } \\
\text { give their } \\
\text { attendance }\end{array}$ \\
\hline Iris-based & $\begin{array}{l}\text { Invades the pri- } \\
\text { vacy of the user }\end{array}$ \\
\hline Wireless-based & $\begin{array}{l}\text { Poor } \\
\text { performance if } \\
\text { topography is } \\
\text { bad }\end{array}$ \\
\hline
\end{tabular}

\section{B. Face Detection}

An appropriate and effective face identification calculation consistently improves face location frameworks execution. Various calculations were proposed for face identification, for example, techniques dependent on facial geometry, highlight invariant strategies, strategies dependent on AI. Viola and Jones have proposed a system of every one of these strategies that gives a high location rate and is likewise quick.

Viola-Jones identification calculation is proficient as it is quick and hearty for ongoing use. 5] We have subsequently picked Viola-Jones face identification calculation utilizing Necessary Picture and AdaBoost learning calculation as a classifier. We saw that in various lighting conditions this calculation gives better outcomes and we joined numerous hair classifiers to accomplish better identification rates up to 30 degrees.

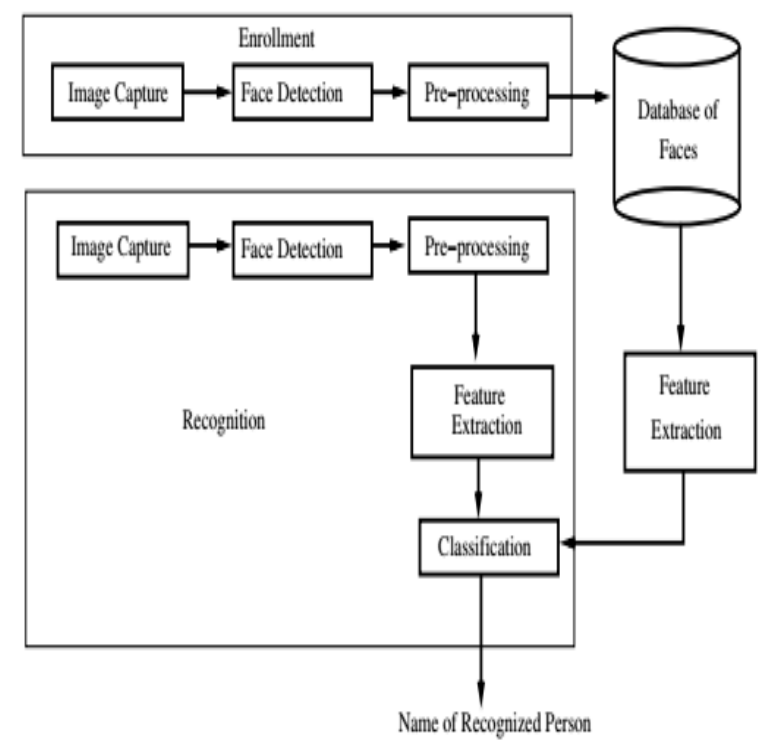

Fig. 1 System Architecture

\section{Pre-processing}

The distinguished face is evacuated and preprocessed. This pre-handling step includes evening out the separated face picture with a histogram and is resized to $100 \times 100$. Histogram Evening out is the most widely recognized strategy of Histogram Institutionalization. This improves the complexity of the picture by making it more clear as it expands the scope of powers in a picture. 


\section{Database Development}

As we have decided to select every individual's biometric-based framework. This advancement period of the extricating the bio-metric element, for our situation it is face, and afterward improving it utilizing pre-preparing procedures and put away in the database. We took singular pictures in various points, various articulations and furthermore in various lighting conditions in our undertaking. For this undertaking, a rundown of 80 people (NITW-database) with 20 pictures of every wa aggregated. Figure 2 shows not many removed faces put away in the database and pre-handled countenances.

\section{E. Feature Extraction and Classification}

A Face Acknowledgment framework's exhibition likewise relies upon the extraction of the component and its grouping to acquire precise outcomes. Utilizing highlight-based systems or comprehensive procedures, extraction of highlights is accomplished. We can utilize dimensionality decrease before arrangement in some all-encompassing strategies. We thought about the consequences of various comprehensive techniques continuously situation used to separate and distinguish highlights. Examination portrayals are given in Table II.

The main calculation speaking to the faces monetarily was Head Segment Investigation (PCA). Utilizing Eigen faces and their relating projections along every Eigen face, the face pictures are spoken to in PCA. Rather than utilizing the whole picture, every one of the components of an item are known to speak to just pertinent measurements. A picture utilizing PCA is spoken to scientifically as

$$
\chi=W Y+\mu
$$

Where $\mathrm{X}$ is the face vector, $\mathrm{Y}$ is the vector of the essence of Eigen, $\mathrm{W}$ is the vector of the capacity, and $\mu$ is the vector of the face. At that point these projections (include vectors) are utilized in face acknowledgment as ID capacities. Later Fisher s Direct Discriminant Examination (LDA) was proposed to advance the proportion of dissipating among class and inside class. PCA doesn't consider the discriminative data in the information when the discriminative data is put away in the information as LDA. In well-lit up condition, LDA can perceive a picture yet bombs in terrible lit up conditions. At times, PCA surpasses LDA and the other way around. 6] As of late, the Nearby Double Example Histogram (LBPH) is proposed as a face extraction calculation. In this procedure, the LBP picture is sectioned into nearby locales and every histogram is separated to frame a face descriptor [7]. Database size impacts the unwavering quality of a framework actualized utilizing PCA and LDA, which isn't the situation with LBP. 8]

When all is said in done, territory classifiers are liable to highlights gotten from PCA and LDA. The separation between the test picture qualities and the prepared picture attributes is resolved. On the off chance that the separation is beneath the point of confinement, the picture of the test will be perceived.

$$
e_{r}=\min \left\|\omega-\omega_{i}\right\|
$$

Where e $\mathrm{r}$ is Euclidean separation, there is a picture vector and $\mathrm{I}$ is a certified picture number. However, for better grouping, we can utilize some AI calculations. PCA is database comprises of catching every individual's picture and

utilized for extraction of highlights and for arrangement; Bolster Vector Machine (SVM) is utilized. As of late, SVM has been proposed as a productive calculation for the grouping of examples. SVM considers the ideal parting of nearest focuses in the preparation set for design acknowledgment. This is a direct or non-straight division. We need a multi-class classification in true situation.

Bolster Vector Grouping, a sort of SVM, is utilized to arrange various classes. Credulous Bayes classifier is a basic classifier that accept a class' qualities are autonomous. Limited quantity of preparing information is adequate for estimation in Bayes Order.

So Face Acknowledgment includes the extraction and grouping of highlights in two phases. In various genuine situations, for example, lighting conditions, Unexpected facial element changes (blocked faces), demeanors, the previously mentioned highlight extractors joined with classifiers are thought about. It additionally assesses framework execution as far as acknowledgment rate, separation, bogus positive rate, time taken for preparing. Bogus positive rates are determined by considering 60 picture outlines in Table II progressively. LBP-based calculation has been seen to give less bogus positive rate and great acknowledgment rate as it accurately separates among obscure and known appearances. Just when segregation is given in the database (for instance, pictures under various lighting conditions) can LDA separate effectively between pictures. In this framework model, separation likewise plays as a paradigm as picture outlines are caught when individuals go into the room and face zone is resized. So for LBPH and different calculations separately, the face district caught at about 4 feet and 7 feet gives better outcomes. Preparing time is determined for a preparation information of 150 pictures. LBP-based calculation requires least preparing time in which SVM and Bayes classifiers take more time to learn. SVM performs preferred order over the rest in classifier differentiate.

\section{F. Post-processing}

After recalling the understudies ' faces, the names are changed to an exceed expectations sheet in the proposed framework. A proviso is likewise included toward the finish of the class to uncover the names of all understudies present in the school. This is finished with the interpretation from content to articulation. The framework is likewise outfitted with the office where that office is empowered to send warning mail to the non-attendants.

Mocking is a significant risk to the facial acknowledgment frameworks. It is in this way remembered for the framework hostile to ridiculing procedure, for example, eye squint identifier. For recognize the squint of the eye, the measure of eye discovery and the quantity of iris Location of the region is differentiated. The occasions the eye is identified in static picture is equivalent to the occasions the iris locale is distinguished or the check of iris district identification is zero 
(if the individual shuts his eyes). For certain number of edges, this tally is expanded.

As appeared in Figure 3, the eyes are expelled from the picture utilizing hair classifiers as appeared in I then the eye area is changed over to a dark picture as appeared in (ii) and the picture is exposed to invert concealment utilizing twofold limit channel (as appeared in (iii)). At that point the iris locale gets a dark scale estimation of 255 and the rest of an estimation of 0 . The switched photograph turns out to be thoroughly dark when the eyes are shut. It is conceivable to figure dependent on this flicker tally.

\section{RESULTS}

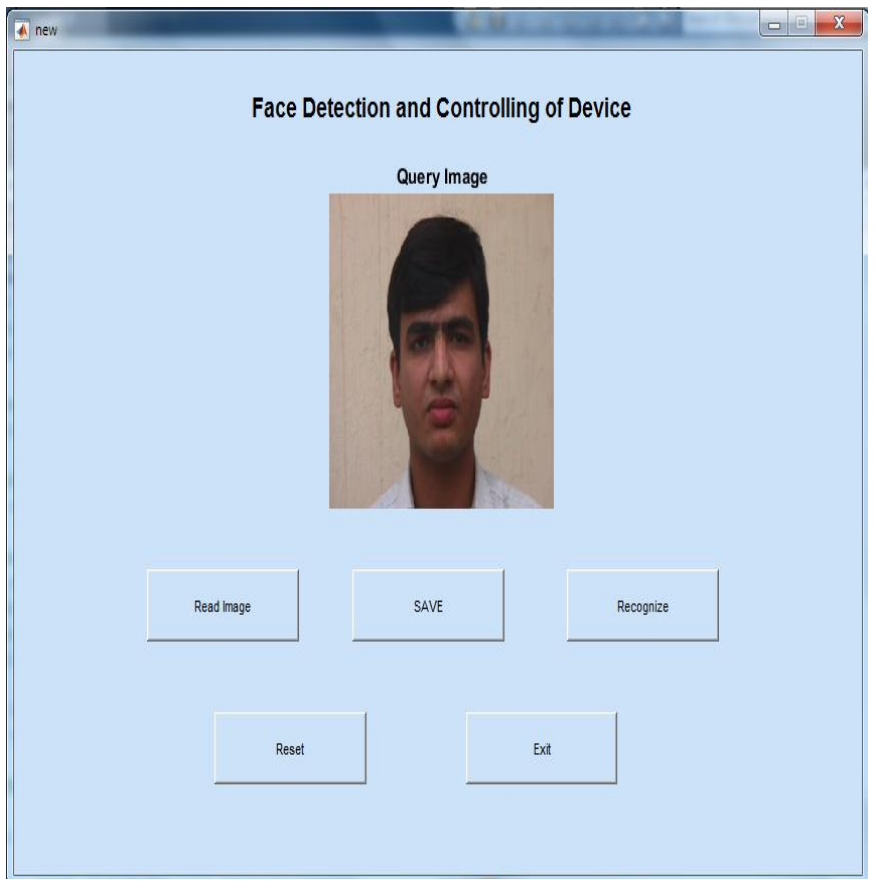

Figure 1

File Edit View Insert Tools Desktor Windov Help s

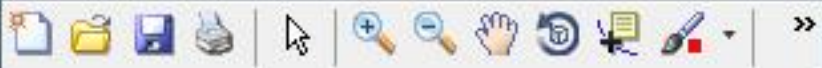

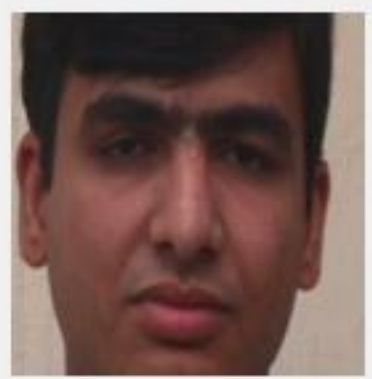

Fig. 1 Extraction and Updating Database

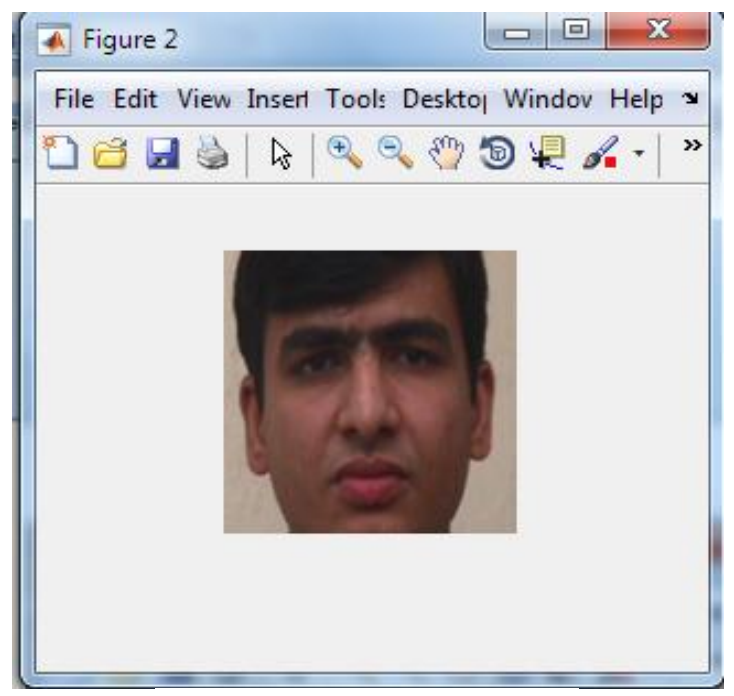

Fig. 2 recognizing the faces

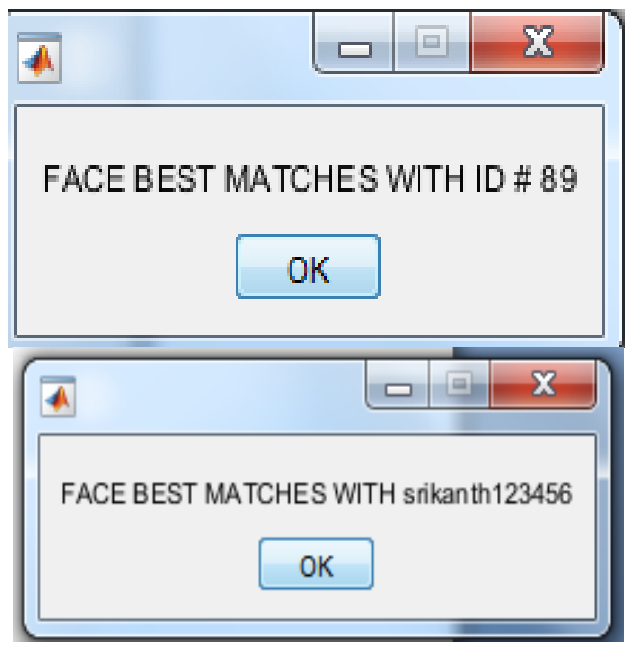

\section{CONCLUSION AND FUTURE WORK}

This has brought about approved efficient and safe mechanized participation frameworks dependent on face acknowledgment procedures. This gadget can likewise be utilized to characterize an obscure individual. LBPH beats different calculations progressively circumstances with higher location rates and low bogus positive rates. Contrasted with separation classifiers, SVM and Bayesian are additionally better classifiers.

Future work is to build the degree of calculation mindfulness when an individual experiences accidental changes, for example, tonsuring head, utilizing scarf, and facial hair. The created framework just perceives face point varieties of up to 30 degrees which need further advancement. Stride acknowledgment can be joined with facial acknowledgment frameworks to accomplish better framework execution.

\section{REFERENCES}

[1] B. K. Mohamed and C. Raghu, "Fingerprint attendance system for classroom needs," in India Conference (INDICON), 2012 Annual IEEE. IEEE, 2012, pp. 433-438.

[2] T. Lim, S. Sim, and M. Mansor, "Rfid based attendance system," in Industrial Electronics \& Applications, 2009. ISIEA 2009. IEEE Symposium on, vol. 2. IEEE, 2009, pp. 778-782. 
[3] S. Kadry and K. Smaili, "A design and implementation of a wireless iris recognition attendance management system," Information Technology and control, vol. 36, no. 3, pp. 323-329, 2007.

[4] T. A. P. K. K. L. P. M. L. M. P. A. W. G. D. P. J. G.. RoshanTharanga, S. M. S. C. Samarakoon, "Smart attendance using real time face recognition," 2013.

[5] P. Viola and M. J. Jones, "Robust real-time face detection," International journal of computer vision, vol. 57, no. 2, pp. 137-154, 2004.

[6] W. Zhao, R. Chellappa, P. J. Phillips, and A. Rosenfeld, "Face recognition: A literature survey," Acm Computing Surveys (CSUR), vol. 35, no. 4, pp. 399-458, 2003.

[7] T. Ahonen, A. Hadid, and M. Pietik"ainen, "Face recognition with local binary patterns," in Computer Vision-ECCV 2004. Springer, 2004, pp. 469-481.

[8] N. A. I. Q. S. Z. Rameez Qasim, M. Mutsaied Shirazi, "Comparison and improvement of pca and lbp efficiency for face recognition," 2013.

[9] M. O. Faruqe and M. Al Mehedi Hasan, "Face recognition using pca and svm," in Anti-counterfeiting, Security, and Identification in Communication, 2009. ASID 2009. 3rd International Conference on IEEE, 2009, pp. 97-101. 